Original Article

\title{
ANTI-PSYCHOTIC ACTIVITY OF PYRUS COMMUNIS JUICE
}

\author{
ARZ00*, MILIND PARLE \\ Pharmacology Division, Department of Pharm. Sciences, Guru Jambheshwar University of Science and Technology, ('A' Grade NAAC \\ accredited, State Govt. University) Hisar 125001 (Haryana) \\ *Email: arzoopannu@gmail.com
}

Received: 07 Aug 2016 Revised and Accepted: 27 Feb 2017

\begin{abstract}
Objective: The present study aim to investigate the anti-psychotic potential of Pyrus communis in the rodents.

Methods: The fresh juice of Pyrus communis (Pear) was administered orally to rodents for $21 \mathrm{~d}$ and the anti-psychotic activity was assessed by in vitro methods viz ketamine induced stereotypic behaviour, pole climbing avoidance in rats and swim induced grooming behaviour experimental models. The biochemical estimation was done on $21 \mathrm{~d}$.

Results: The different concentrations of fresh Pyrus communis juice was assayed. When Pyrus communis juice (PCJ) was administered chronically for $21 \mathrm{~d}$ remarkably decreased ketamine induced falling, head-bobbing, weaving and turning counts. Administration of Pear juice significantly delayed the latency time taken by the animals to climb the pole in Cook's pole climb apparatus. In swim induced grooming behaviour model, Pear juice significantly reduced swim induced grooming behaviour. Moreover, Pear juice significantly decreased the brain dopamine levels and inhibited acetyl cholinesterase activity. In the present study, Pear juice significantly enhanced reduced glutathione levels in the brains of mice, thereby reflecting enhanced scavenging of free radicals and in turn preventing occurrence of psychotic attack.
\end{abstract}

Conclusion: The present study revealed that Pyrus communis juice possessed significant anti-psychotic activity.

Keywords: Pear Juice, Pyrus communis juice, Antioxidant, Psychosis, Dopamine

(C) 2017 The Authors. Published by Innovare Academic Sciences Pvt Ltd. This is an open access article under the CC BY license (http://creativecommons.org/licenses/by/4. 0/) DOI: http://dx.doi.org/10.22159/ijpps.2017v9i4.14541

\section{INTRODUCTION}

Nature has blessed us with a wonderful flora and fauna, which has made our life lovely. One of these wonders is Pear fruit. Pear belongs to dicotyledonous plant species of genus Pyrus communis, (Family: Rosaceae) [1]. Pear is full of precious phytoconstituents viz. glycosides, vitamins, minerals, amino acids, fatty acids, flavonoids, alkaloids, polyphenols and tannins [2]. Each part of Pear tree has high nutritional value and possesses multiple medicinal properties such as anti-inflammatory, sedative, antipyretic, antioxidant, hypolipidemic, hypoglycaemic, anti-aging, analgesic, spasmolytic, anti-tussive, anti-diarrheal, wound healing, anti-microbial and hepatoprotective [1].

It holds $2^{\text {nd }}$ rank after apple in nutrition amongst cultivated fruits. As Pear is a rich source of vitamin C, quercetin and copper, which protect cells from damage by free radicals [3]. Pear maintains folic acid levels during pregnancy and prevents the development of birth defects in babies. Pear is recommended for weaning babies, which aren't too harsh on a baby's digestive system. Pear is useful in dysmenorrhea when taken regularly. Pear also possesses promising neuroprotective properties thereby preventing the development of neurodegenerative diseases such as Parkinsonism, Huntington's disease and Alzheimer's disease [1]. Regular consumption of Pear lowers the risk of age-related macular degeneration, which is the main cause of vision loss in older adults.

Schizophrenia continues to be a mysterious disease, fascinating the minds of psychiatrists, pharmacologists and neuroscientists all over the world for more than a century. Schizophrenia is a disabling condition having onset earlier in men (15-25 y.) than in women (25$35 \mathrm{yrs}$ ), with a lifetime global prevalence of $1 \%$. A typical patient of schizophrenia experiences four types of clinical symptoms a) Apathetic attitude such as lack of emotions, flat affect, expressionless gaze b) Bizarre behaviour such as disorganized conduct, hostility, unnecessary laughter or crying episodes, odd or irrational statements, strange way of speaking, deterioration of personal hygiene, delusions, hallucinations, suspicious nature, c) Cognitive dysfunctions such as aphasia, irrelevant talk, dementia, loss of concentration, lack of judgement, d) Depressive symptoms such as lack of motivation, social withdrawal, anhedonia, insomnia, lack of interest in life, self-harm etc [4].

Nutritional therapy is a healing system using functional foods and nutraceuticals as therapeutics. This complementary therapy is based upon the assumption that plants are not only a source of fruits and vegetables but can also provide health benefits. Consumed as part of a normal diet, plant foods are thus not only a source of nutrients and energy but may additionally provide health benefits beyond basic nutritional functions. Therefore, this project was undertaken to investigate antipsychotic potential of Pear fruit in small laboratory animals.

\section{MATERIALS AND METHODS}

\section{Plant material}

The fresh Pear fruit (Pyrus communis) was collected from Hisar market and got authenticated from Department of Horticulture, Haryana University of Agriculture, Hisar (Ref. Hort. R-1740/2016-7). Pear juice was administered in different doses $(50 \% \mathrm{v} / \mathrm{v}, 100 \% \mathrm{v} / \mathrm{v}$, p. o) to mice and rats.

\section{Experimental animals}

A total of 66 adult Swiss mice divided in 11 groups weighing around $20-25 \mathrm{~g}$ and 30 Wistar male rats divided in 5 groups weighing around 180-200g were procured from Disease Free Small Animal House, Lala Lajpat Rai University of Veterinary and Animal Sciences, Hisar. All the animals were housed in Psychopharmacology laboratory under controlled conditions of temperature in a natural $12 \mathrm{~h}$ each light-dark cycle. Water boiled wheat porridge (dalia) was given to the animals as food. The animals were acclimatized for at least $5 \mathrm{~d}$ to the laboratory conditions before behavioural experiments. Experiments were carried out between 09:00 am to 5:00 pm. The experimental protocol was approved by the Institutional Animals Ethics Committee (IAEC) and the care of animals was taken as per guidelines of CPCSEA, Ministry of Forests and Environment, Government of India (Registration number 0436). 
Each observation was recorded in a separate group of mice/rats. Each group consisted of six animals, and each animals was used only once in the study.

\section{Drug protocol}

Haloperidol, $1 \mathrm{mg} / \mathrm{kg}$, i. p. (RPG Science Pharmaceutical Pvt. Ltd), olanzapine, $5 \mathrm{mg} / \mathrm{kg}$, i. p. (Intas Pharmaceuticals Ltd) and ketamine, 50 $\mathrm{mg} / \mathrm{kg}$, i. p. (Troikaa Pharmaceuticals Ltd) were administered daily for the duration of $21 \mathrm{~d}$ to the animals. Saline was injected to control group for 21 consecutive days. Ketamine ( $50 \mathrm{mg} / \mathrm{kg}$, i. p) was injected for 21 consecutive days for inducing stereotypic behaviour.

\section{Laboratory models employed for testing psychosis}

\section{I) Ketamine-induced stereotypic behaviour in mice [5]}

In this model, animals were divided into seven groups, and each group consisted of six animals. The control group I received only saline $(1 \mathrm{ml} / \mathrm{kg}$, i. p) and negative control group II received ketamine $(50 \mathrm{mg} / \mathrm{kg}$, i. p). The animals of groups III, IV received haloperidol (1 $\mathrm{mg} / \mathrm{kg}$, i. p) and olanzapine $(5 \mathrm{mg} / \mathrm{kg}$, i. p) respectively and after 30 min ketamine $(50 \mathrm{mg} / \mathrm{kg}$, i. p) was given, for 21 consecutive days. Group V received Pyrus communis juice only ( $100 \% \mathrm{v} / \mathrm{v}, \mathrm{p}$. o.) for 21 d. The animals of test groups VI and VII received different concentrations of Pyrus communis juice (50\% v/v, $100 \%$ v/v, p. o) respectively and after $30 \mathrm{~min}$ ketamine was given $(50 \mathrm{mg} / \mathrm{kg}$, i. p) for 21 consecutive days. Each mouse was individually placed into a separate plastic cage $\left(37 \times 24 \times 30 \mathrm{~cm}^{3}\right)$, which was divided into quadrants by lines on the floor and was allowed to acclimatize for at least $30 \mathrm{~min}$ before the experiments. Behavioural tests were performed between 9 am to $4 \mathrm{pm}$.

The stereotypic behaviour was assessed by counting the number of turning, weaving, and head bobbing counts. Turning was measured by counting turnaround attempt of each mouse every 10 min over 60 min period. Weaving and Head-bobbing counts were measured by counting its neck movements towards the right and left, and up and down every $10 \mathrm{~min}$ over $60 \mathrm{~min}$. Ataxia was assessed by counting the number of falls every 10 min over $60 \min [6]$.

\section{II) Pole climbing avoidance in rat [7]}

In this model, animals were divided into five groups and each group consisted of six animals. The control group VIII received only the vehicle. The animals of groups IX and $X$ received haloperidol (1 $\mathrm{mg} / \mathrm{kg}$, i. p) and olanzapine $(5 \mathrm{mg} / \mathrm{kg}$, i. p) respectively for 21 consecutive days. The animals of test groups $\mathrm{XI}$ and XII received different concentrations of Pyrus communis juice $(50 \% \mathrm{v} / \mathrm{v}, 100 \% \mathrm{v} / \mathrm{v}, \mathrm{p} . \mathrm{o})$ respectively, for 21 consecutive days. The pole-climb avoidance paradigm is an avoidance-escape procedure used to separate neuroleptics from sedatives and anxiolytics.

Whereas sedative compounds suppress both avoidances and escape responding at approximately the same doses, neuroleptic drugs reduce avoidance at lower doses than those affecting escape responding. Male wistar rats weighing around 150 gm were used in the training and testing of the rat was conducted in the Pole climbing apparatus, which has a floor that acts as a source of shock. At the centre of the instrument, there is a wooden pole, which also serves as a shock free zone. The procedure and endpoint observed in the present study were as described earlier [7]. Data were expressed in terms of the number of avoidance attempts and escape failures relative to the respective vehicle control group.

\section{III) Swim induced grooming in mice [8]}

In this model, the control group XIII received only the vehicle. The animals of group IXV received haloperidol $(1 \mathrm{mg} / \mathrm{kg}$, i. p), for 21 consecutive days. The animals of test groups XV and XVI received different concentrations of Pyrus communis juice (50\% v/v, $100 \%$ $\mathrm{v} / \mathrm{v}, \mathrm{p}$. o) respectively, for 21 consecutive days. Sixty minutes after treatments, mice were placed individually in swimming cylinders $\left(8 \times 8 \times 18 \mathrm{~cm}\right.$ high) filled with water $\left(32^{\circ} \mathrm{C}\right)$ for three min. They were then removed and dried with a towel for 30 seconds and placed immediately into Perspex boxes individually. The number and the total duration of grooming attempts were recorded over $15 \mathrm{~min}$. period as described in the literature [8].

\section{Biochemical estimation}

Estimation of brain neurotransmitters and glutathione levels

The animals were sacrificed by cervical decapitation under light anaesthesia on $22^{\text {nd }}$ day $90 \mathrm{~min}$ after drugs administration. Immediately after decapitation, the whole brain was dissected out. Brain dopamine levels [9], brain AChE activity [10], and brain glutathione [11] levels were estimated as per the procedure described earlier in literature.

\section{Statistical analysis}

All values were expressed as mean \pm SEM the data were analyzed using one-way ANOVA followed by Dunnett's t-test. $\mathrm{p}<0.05$ was considered to be statistically significant.

\section{RESULTS}

\section{Preliminary studies}

Pyrus communis juice was administered orally to mice in different concentrations in preliminary studies to delineate optimally effective concentrations for further studies.

\section{A. Effect of Pyrus communis juice on ketamine-induced stereotypic behavior of mice}

The stereotypic behavior was assessed by measuring the number of turning, weaving, falling and head-bobbing counts produced by mice. Turning behavior was measured by counting the turnaround of each mouse every $10 \mathrm{~min}$ over $60 \mathrm{~min}$ period. Weaving behavior was measured by counting its paw movements and standing on hind legs attempts every 10 min over 60 min period.

Head-bobbing behavior was measured by counting its neck movements towards right/left and up/down every 10 min over 60 min period. Falling was assessed by counting the number of falls of each mouse on the floor of the cage every 10 min over 60 min period.

Ketamine $(50 \mathrm{mg} / \mathrm{kg}$, i. p) successfully evoked above described stereotypic behavior in mice. Pyrus communis juice, when administered at $50 \% \mathrm{v} / \mathrm{v}$ and $100 \% \mathrm{v} / \mathrm{v}$ concentrations orally for 21 successive days remarkably $(\mathrm{p}<0.01)$ decreased this stereotypic behavior of mice produced by Ketamine. Administration of Pyrus communis juice per se didn't evoke any stereotypic behaviour in mice. Animals pre-treated with haloperidol $(1 \mathrm{mg} / \mathrm{kg}$, i. p) and olanzapine $(5 \mathrm{mg} / \mathrm{kg}$, i. p) reduced the stereotypic behaviour induced by Ketamine. The effect of Pyrus communis juice was found to be comparable to that of Haloperidol and Olanzapine (Marketed antipsychotic agents).

\section{i) Effect of Pyrus communis juice on turning behavior of mice}

Administration of Pyrus communis juice per se didn't evoke any turning behaviour in mice. Administration of Pyrus communis juice (p. o for $21 \mathrm{~d})$ at the concentration of $50 \% \mathrm{v} / \mathrm{v}(\mathrm{p}<0.05)$ and $100 \% \mathrm{v} / \mathrm{v} \quad(\mathrm{p}<0.01)$ dose-dependently decreased the turning behavior of mice induced by Ketamine. Animals pretreated with haloperidol (1 $\mathrm{mg} / \mathrm{kg}$, i. p) and olanzapine (5 $\mathrm{mg} / \mathrm{kg}$, i. p) also decreased the turning pattern of mice as expected (fig. 1).

\section{ii) Effect of Pyrus communis juice on weaving behavior of} mice

Administration of Pyrus communis juice per se didn't evoke any weaving behaviour in mice. Administration of Pyrus communis juice (p. o for $21 \mathrm{~d}$ ) at the concentration of $50 \% \mathrm{v} / \mathrm{v}(\mathrm{p}<0.05)$ and $100 \%$ $\mathrm{v} / \mathrm{v}(\mathrm{p}<0.01)$ dose-dependently decreased the weaving behavior of mice induced by Ketamine. Animals pre-treated with Haloperidol (1 $\mathrm{mg} / \mathrm{kg}$, i. p) and Olanzapine $(5 \mathrm{mg} / \mathrm{kg}$, i. p) also decreased the weaving pattern exhibited by mice (fig. 2). 


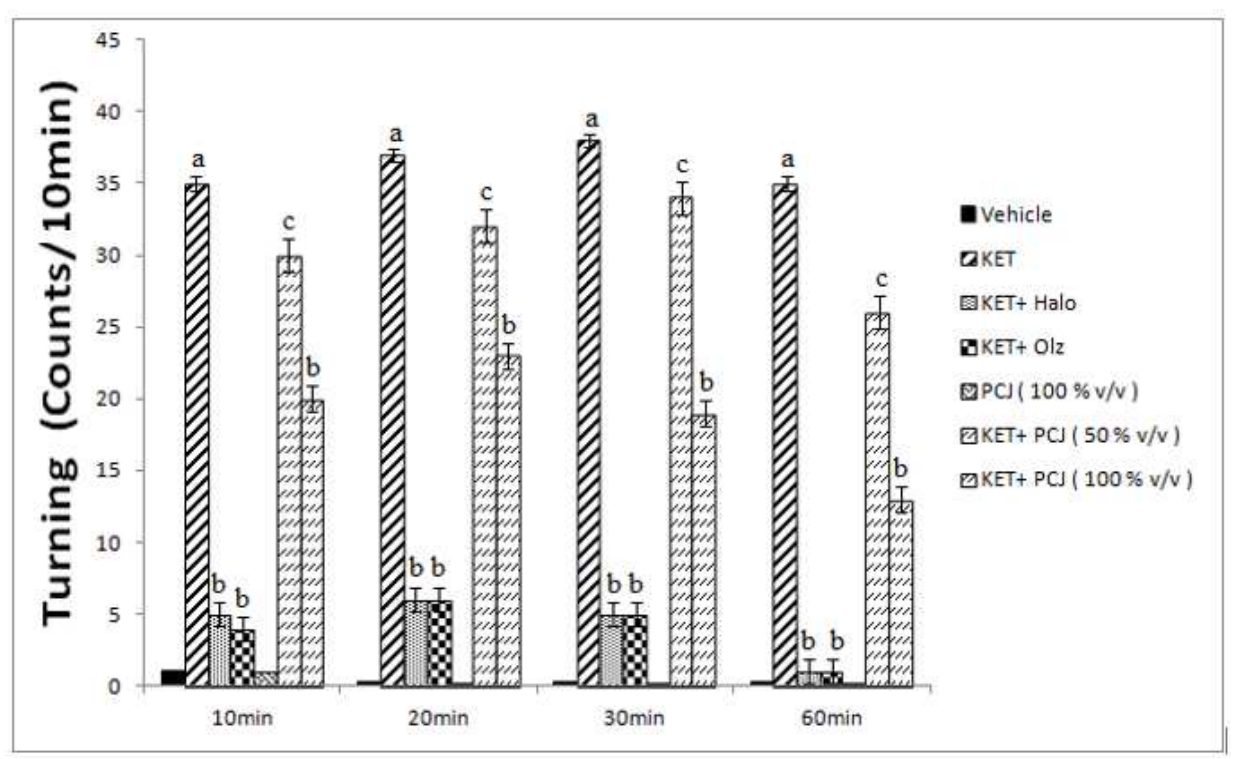

Fig. 1: Effect of Pyrus communis juice on Ketamine-induced turning behavior of mice, when observed every 10 min. over 60 min. Period Values are in mean \pm SEM (number of animals in each groups $=6$ ), a denotes $p<0.01$ as compared to control (Vehicle) group., $b$ denotes p $<0.01$ as compared to Ketamine group., $\mathbf{c}$ denotes $\mathbf{p}<\mathbf{0 . 0 5}$ as compared to Ketamine group., $\mathrm{KET}=\mathrm{Ketamine}, \mathrm{Halo}=\mathrm{Haloperidol,} \mathbf{0 l z}=$ Olanzapine, $\mathrm{PCJ}=$ Pyrus communis Juice, Pyrus communis juice was administered at $50 \% \mathrm{v} / \mathrm{v}$ and $100 \% \mathrm{v} / \mathrm{v}$ per orally for $21 \mathrm{~d}$. , Statistical analysis was carried out by one-way ANOVA followed by Dunnett's t-test

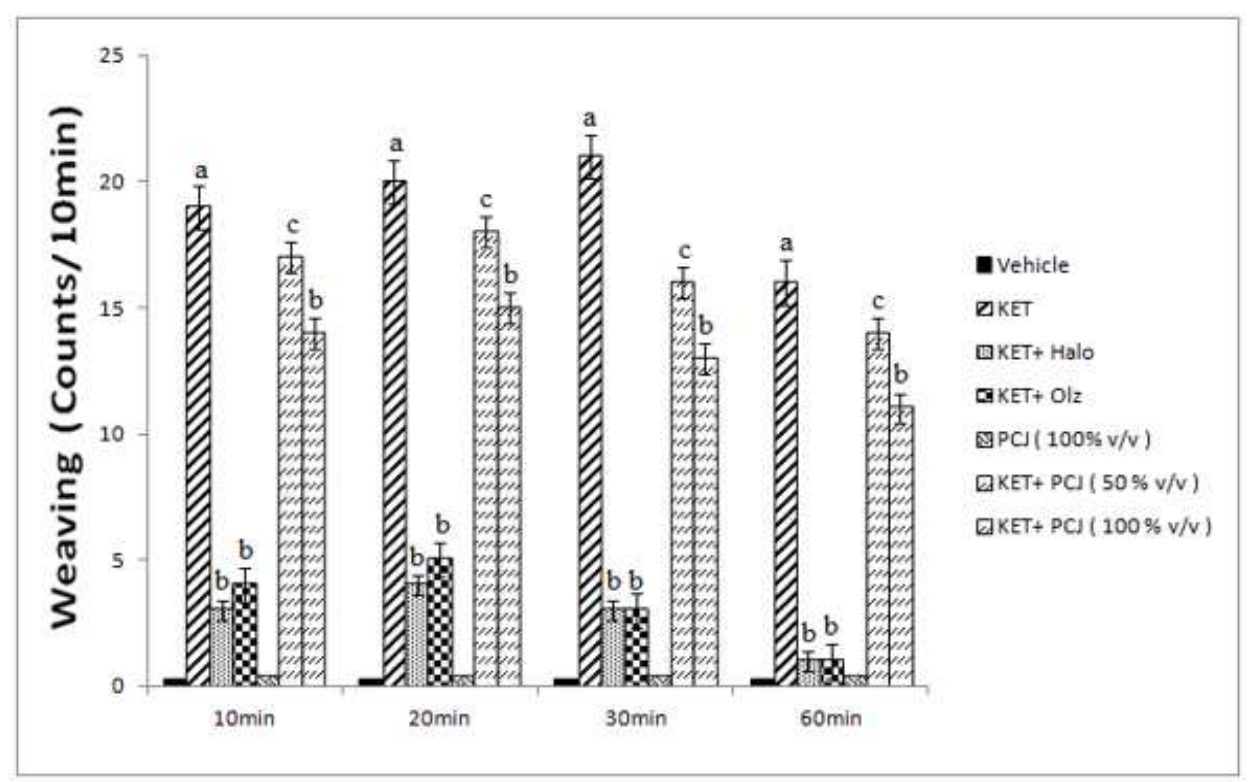

Fig. 2: Effect of Pyrus communis juice on Ketamine-induced weaving behavior of mice, when observed every $10 \mathrm{~min}$. over $60 \mathrm{~min}$. Period Values are in mean \pm SEM (number of animals in each groups $=6$ ), a denotes $\mathbf{p}<0.01$ as compared to control (Vehicle) group, b denotes $\mathbf{p}<\mathbf{0 . 0 1}$ as compared to Ketamine group, $\mathbf{c}$ denotes $\mathbf{p}<\mathbf{0 . 0 5}$ as compared to Ketamine group, $\mathrm{KET}=\mathrm{Ketamine}, \mathrm{Halo}=\mathrm{Haloperidol}, \mathrm{Olz}=$ Olanzapine, $\mathrm{PCJ}=$ Pyrus communis Juice, Pyrus communis juice was administered at $50 \% \mathrm{v} / \mathrm{v}$ and $100 \% \mathrm{v} / \mathrm{v}$ per orally for $21 \mathrm{~d}$, Statistical analysis was carried out by one-way ANOVA followed by Dunnett's t-test

iii) Effect of Pyrus communis juice on head-bobbing behavior of mice

Administration of Pyrus communis juice per se didn't evoke any headbobbing behaviour in mice. Administration of Pyrus communis juice (p. o for $21 \mathrm{~d}$ ) at the concentration of $50 \% \mathrm{v} / \mathrm{v}$ showed no significant decrease in the head-bobbing behavior of mice induced by Ketamine. However, at the concentration of $100 \% \mathrm{v} / \mathrm{v}(\mathrm{p}<0.01)$ there was a decrease in the head-bobbing behavior of mice induced by Ketamine. Animals pretreated with Haloperidol (1 mg/kg, i. p) and Olanzapine $(5 \mathrm{mg} / \mathrm{kg}$, i. p) also decreased the head-bobbing counts in mice (fig. 3 ).

\section{iv) Effect of Pyrus communis on falling behavior of mice}

Administration of Pyrus communis juice per se didn't evoke any falling behaviour in mice. Administration of Pyrus communis juice (p. o for $21 \mathrm{~d}$ ) at the concentration of $50 \% \mathrm{v} / \mathrm{v}$ showed no significant decrease in the falls of mice induced by Ketamine. However, at the concentration of $100 \% \mathrm{v} / \mathrm{v}(\mathrm{p}<0.01)$ there was a decrease in the head-bobbing behavior of mice induced by Ketamine. Animals pre-treated with Haloperidol $(1 \mathrm{mg} / \mathrm{kg}$, i. p) and Olanzapine (5 mg/kg, i. p) also decreased the falling behaviour (fig. 4). 


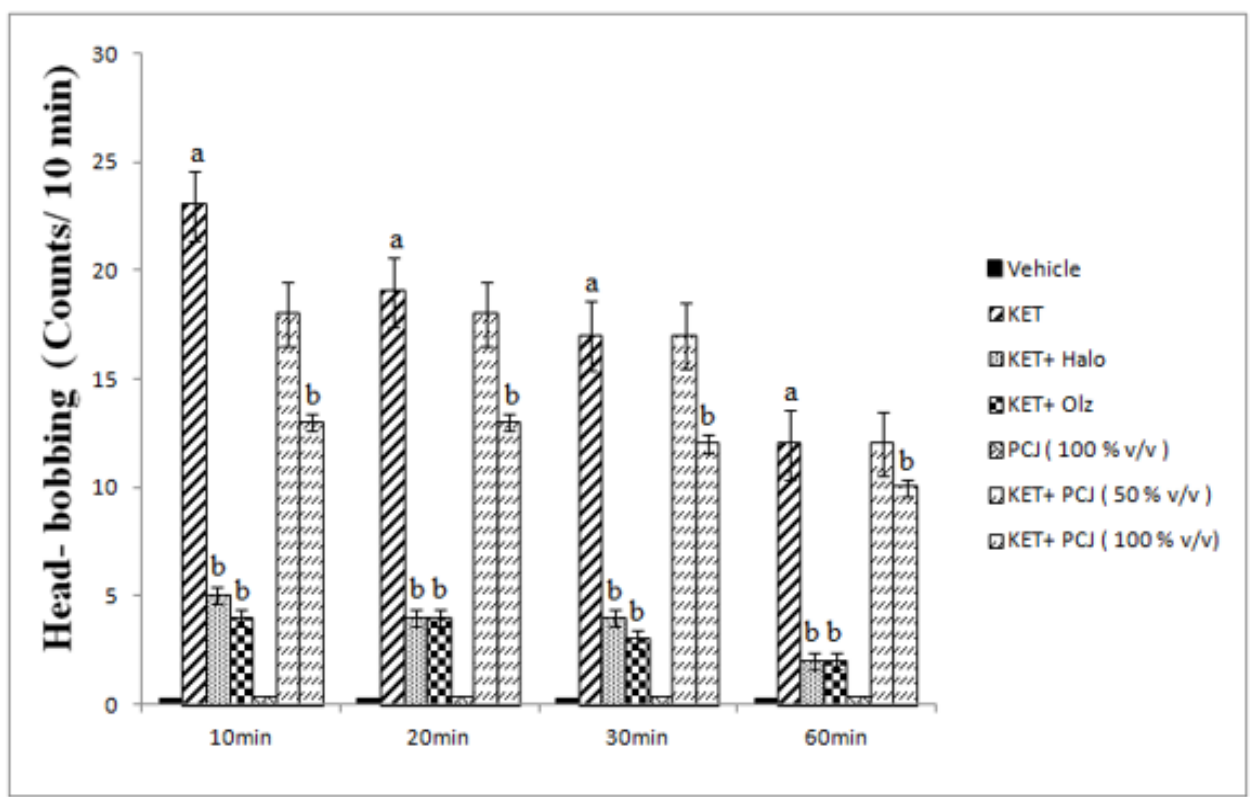

Fig. 3: Effect of Pyrus communis juice on Ketamine-induced head-bobbing behavior of mice, when observed every $10 \mathrm{~min}$. over $60 \mathrm{~min}$. Period Values are in mean \pm SEM (number of animals in each groups $=6$ ), a denotes $p<0.01$ as compared to control (Vehicle) group, $b$ denotes $p<0.01$ as compared to Ketamine group, $\mathrm{KET}=$ Ketamine, $\mathrm{Halo}=\mathrm{Haloperidol,} \mathrm{Olz}=$ Olanzapine, $\mathrm{PC}=$ = Pyrus communis Juice, Pyrus communis juice was administered at $50 \% \mathrm{v} / \mathrm{v}$ and $100 \% \mathrm{v} / \mathrm{v}$ per orally for $21 \mathrm{~d}$, Statistical analysis was carried out by one-way ANOVA followed by Dunnett's t-test

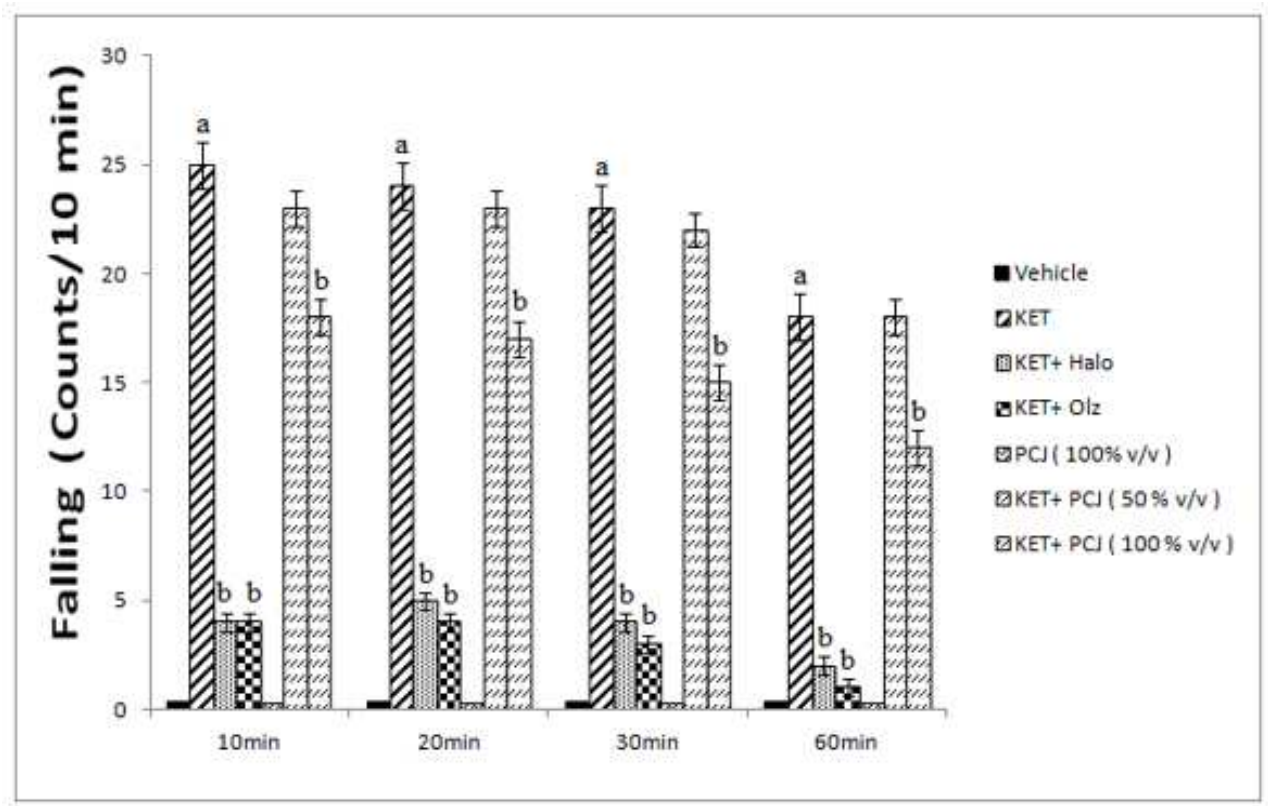

Fig. 4: Effect of Pyrus communis juice on Ketamine-induced falling behavior of mice, when observed every $10 \mathrm{~min}$. over $60 \mathrm{~min}$. Period Values are in mean \pm SEM (number of animals in each groups $=6$ ), a denotes $p<0.01$ as compared to control (Vehicle) group, $b$ denotes $\mathbf{p}<0.01$ as compared to Ketamine group, $\mathrm{KET}=$ Ketamine, Halo $=$ Haloperidol, $\mathbf{O l z}=$ Olanzapine, Pyrus communis juice was administered at $50 \% \mathrm{v} / \mathrm{v}$ and $100 \% \mathrm{v} / \mathrm{v}$ per orally for $21 \mathrm{~d}$, Statistical analysis was carried out by one-way ANOVA followed by Dunnett's t-test

\section{B. Effect of Pyrus communis juice on pole climb avoidance in rats}

Administration of Pyrus communis juice (p. o) at the concentration of $100 \% \mathrm{v} / \mathrm{v}$ remarkably $(\mathrm{p}<0.01)$ inhibited the conditioned avoidance response in rats as indicated by increased time spent on the grid floor of the chamber (fig. 5). However, Pyrus communis juice at the concentration of $50 \% \mathrm{v} / \mathrm{v}$ significantly $(\mathrm{p}<0.05)$ inhibited the conditioned avoidance response. The effect of Pyrus communis juice was found to be comparable to that of antipsychotic agents, Haloperidol (1 mg/kg, i. p.) and Olanzapine (5 mg/kg, i. p.).
C. Effect of Pyrus communis juice on swim-induced grooming in mice

Pyrus communis juice, at the concentration of $50 \% \mathrm{v} / \mathrm{v}$ (p. o for $21 \mathrm{~d}$ ) significantly $(p<0.05)$ decreased the number of grooming attempts of mice as compared to the control group. However, at the concentration of $100 \% \mathrm{v} / \mathrm{v}$ (p. o for $21 \mathrm{~d}$ ), Pyrus communis juice remarkably $(p<0.01)$ reduced the number of swim-induced grooming attempts (fig. 6) of mice as compared to the control group when administered for 21 consecutive days. 


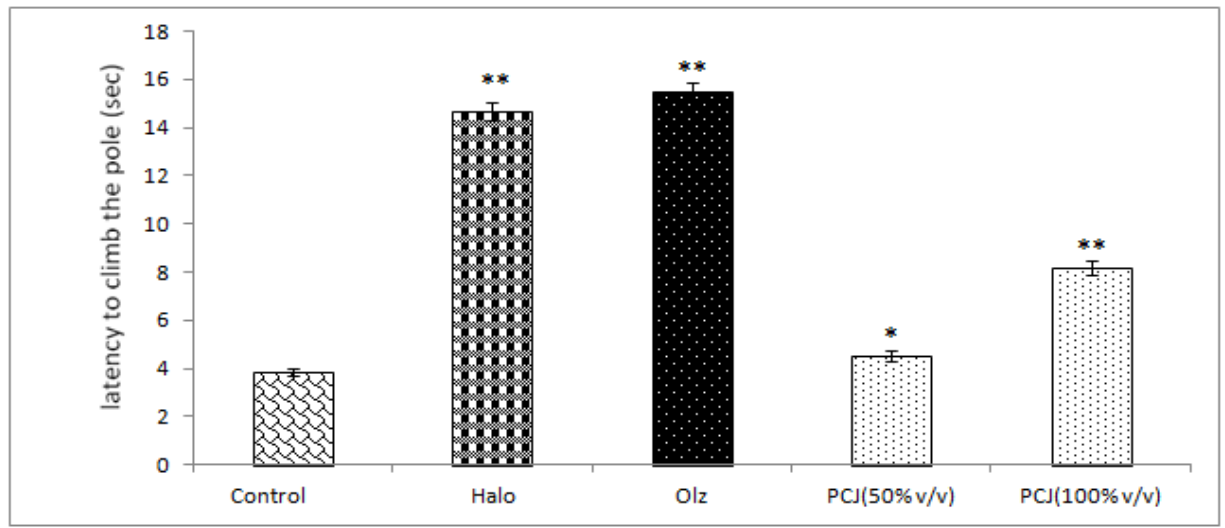

Fig. 5: Effect of Pyrus communis juice on time taken by rats to climb the pole

Values are in mean \pm SEM (number of animals in each groups $=6$ ), ${ }^{* *}$ denotes $\mathbf{p}<0.01$ as compared to control group, $*$ denotes p<0.05 as compared to control group, Halo = Haloperidol, $01 \mathrm{z}=$ Olanzapine, Pyrus communis juice was administered at $50 \% \mathrm{v} / \mathrm{v}$ and $100 \% \mathrm{v} / \mathrm{v}$ per orally for $21 \mathrm{~d}$, Statistical analysis was carried out by one-way ANOVA followed by Dunnett's t-test

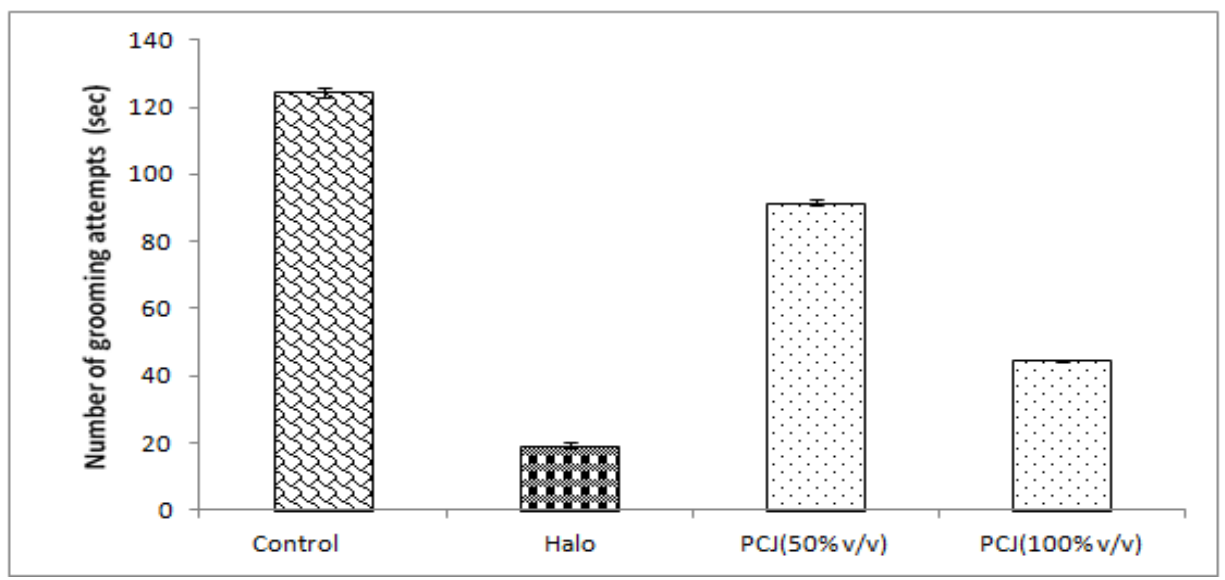

Fig. 6: Effect of Pyrus communis juice on number of grooming attempts of mice in swim-induced grooming model

Values are in mean \pm SEM (number of animals in each groups $=6$ ), ${ }^{* *}$ denotes $\mathbf{p}<0.01$ as compared to control group, ${ }^{*}$ denotes $p<0.05$ as compared to control group, Halo = Haloperidol, Pyrus communis juice was administered at $50 \% \mathrm{v} / \mathrm{v}$ and $100 \% \mathrm{v} / \mathrm{v}$ per orally for $21 \mathrm{~d}$, Statistical analysis was carried out by one-way ANOVA followed by Dunnett's t-test

\section{Effect of Pyrus communis juice on brain dopamine level}

Administration of Pyrus communis juice (p. o) at the concentration of $100 \% \mathrm{v} / \mathrm{v}$ for 21 consecutive days showed significant $(\mathrm{p}<0.05)$ decrease in brain dopamine levels of rodents as compared to the control group (fig. 7)
E. Effect of Pyrus communis juice on brain acetyl cholinesterase activity

Administration of Pyrus communis juice (p. o) at the concentration of $100 \% \mathrm{v} / \mathrm{v}$ for 21 consecutive days showed significant $(\mathrm{p}<0.05)$ decrease in brain Acetylcholinesterase activity in rodents as compared to control group (fig. 8).

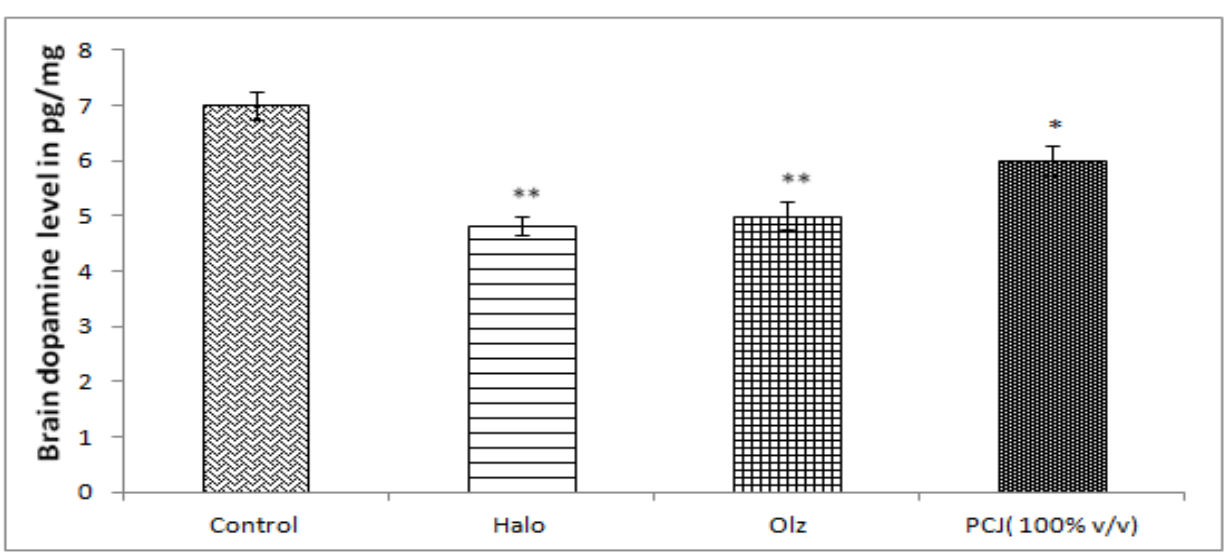

Fig. 7: Effect of Pyrus communis juice on brain Dopamine levels

Values are in mean \pm SEM (number of animals in each groups $=6$ ), ${ }^{* *}$ denotes $\mathbf{p}<0.01$ as compared to control group, ${ }^{*}$ denotes $\mathbf{p}<0.05$ as compared to control group, Halo = Haloperidol, $0 l z=$ Olanzapine, Pyrus communis juice was administered at $100 \% \mathrm{v} / \mathrm{v}$ per orally for $21 \mathrm{~d}$, Statistical analysis was carried out by one-way ANOVA followed by Dunnett's t-test 


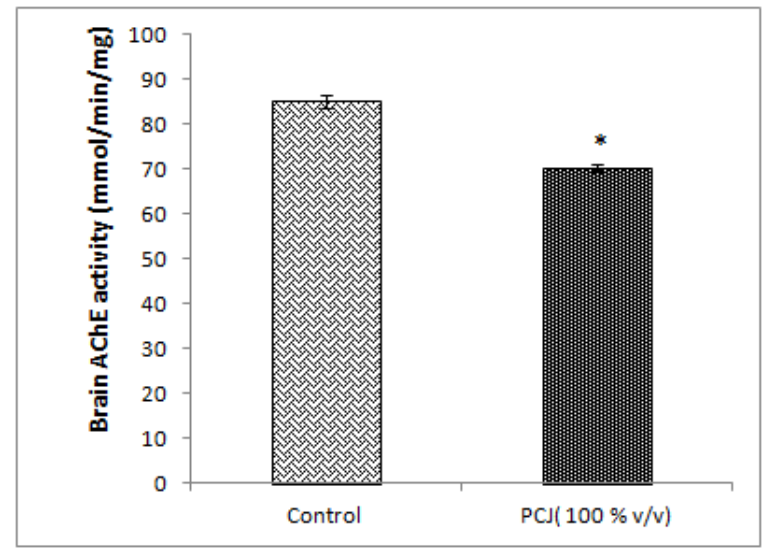

Fig. 8: Effect of honey on brain AchE levels Values are in mean \pm SEM (number of animals in each groups = 6), $*$ denotes $\mathbf{p}<0.05$ as compared to control group, Pyrus communis juice was administered at $100 \% \mathrm{v} / \mathrm{v}$ per orally for 21 d, Statistical analysis was carried out by one-way ANOVA followed by Dunnett's t-test

\section{F. Effect of Pyrus communis juice on brain glutathione level}

Administration of Pyrus communis juice (p. o) at the concentration of $100 \% \mathrm{v} / \mathrm{v}$ for 21 consecutive days showed remarkable $(\mathrm{p}<0.01)$ increase in brain Glutathione level in rodents as compared to control group (fig. 9)

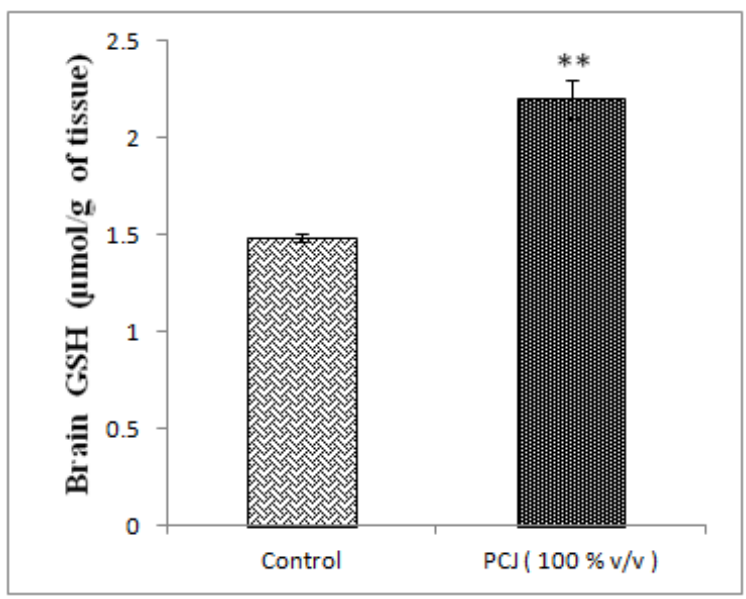

Fig. 9: Effect of Pyrus communis juice on brain GSH levels Values are in mean \pm SEM (number of animals in each groups $=$ 6), **denotes $\mathbf{p}<0.01$ as compared to control group, Pyrus communis juice was administered at $100 \% \mathrm{v} / \mathrm{v}$ per orally for 21

d, Statistical analysis was carried out by one-way ANOVA followed by Dunnett's t-test

\section{DISCUSSION}

Schizophrenia is a common and debilitating illness, characterised by chronic psychotic symptoms and psycho-social impairment that attacks the most advanced functions of the human brain. Schizophrenia has a multifactorial aetiology with multiple susceptibility genes interacting with environmental insults. A typical patient of schizophrenia experiences four types of clinical symptoms a) Apathetic attitude such as lack of emotions, flat affect, expressionless gaze b) Bizarre behaviour such as disorganized conduct, hostility, unnecessary laughter or crying episodes, odd or irrational statements, extreme reactivity, strange way of speaking, deterioration of personal hygiene, suspiciousness, c) Cognitive dysfunctions such as aphasia, irrelevant talk, dementia, loss of concentration, delusions, hallucinations, lack of judgement, d) Depressive symptoms such as lack of motivation, social withdrawal, anhedonia, insomnia, lack of interest in life, self-harm etc [4]. Schizophrenia is related to neurodevelopmental, structural and behavioural abnormalities. It has been proposed that such abnormalities could originate from malfunctioning genes or nongenetic factors such as ethnicity, alcohol-abuse, erratic lifestyle, medications, prenatal and neonatal infections, maternal malnutrition, complications during birth, etc [12]. Oxidative stress is the condition arising from an imbalance between toxic reactive oxygen species and antioxidant systems [13]. Brain tissue also displays higher susceptibility to oxidative damage. Additionally, the brain has a high store of fatty acids. Human brain encounters a high percentage of oxygen consumption, eventually generating an excessive amount of reactive oxygen species (ROS) when compared to other tissues. ROS are constantly produced during oxidative metabolism, which enhances oxidative stress leading to cell damage and death. In the condition of schizophrenia, the balance between the ROS and the antioxidant system is disturbed [14]. Exogenous antioxidants such as those present in Pear juice protect cells from the damage caused by ROS, as they interact with free radicals and prevent some of the neuronal damage. Experimental studies have shown that phenolic compounds, vitamin A, vitamin C, vitamin E, quercetine and flavonoids present in Pear are important antioxidants and superoxide scavengers. Oxidation is a chemical reaction that transfers electrons from a substance to an oxidizing agent. Oxidation reactions can produce free radicals, which start chain reactions that damage cells. Antioxidants terminate these chain reactions by removing free radical intermediates and inhibit other oxidation reactions by being oxidized themselves. When a specific anti-oxidant meets a free radical in the bloodstream at its appropriate activity site, it naturally combines with it and converts the free radical into harmless water and oxygen. GSH is highly abundant in all cell compartments and is the major soluble antioxidant. The ratio between oxidized glutathione and reduced glutathione is one of the important determinants of oxidative stress in the body [15]. In the present study, $P C J$, when administered for 21 $\mathrm{d}$ significantly enhanced reduced glutathione levels in the brains of mice. This finding indicated that $P C J$ enhanced scavenging of free radicals in the brain, thereby preventing the occurrence of a psychotic attack. Vitamin C, which has powerful antioxidant capacity can reduce and thereby neutralize, reactive oxygen species such as hydrogen peroxide [15]. It converts vitamin $\mathrm{E}$ free radicals back to vitamin E. Vitamin E is a fat-soluble vitamin with antioxidant properties. Vitamin E protects cells from oxidation by reacting with lipid radicals produced in the lipid peroxidation chain reaction and also inhibits free radical formations [15]. Selenium present in pear juice is a mineral, and not an antioxidant [15]. However, it is a component of antioxidant enzymes thereby facilitating the antioxidant activity of other antioxidants. Carotenoids show antioxidant property by neutralizing peroxyl, hydroxyl, and superoxide radicals. There are at least three possible mechanisms for the reaction of Carotenoids with radical species. They include (1) radical addition; (2) electron transfer to the radical; and/or (3) allylic hydrogen abstraction [16]. Additionally, they are able to deactivate sensitizer molecules, which are involved in the generation of ROS.

Phytopharmaceuticals are gaining importance in modern medicine as well as in the traditional system of medicine owing to their therapeutic potential. In the present study, we have focussed upon the effects of Pear juice on psychosis. The phytoconstituents present in $P C J$ include glycosides, vitamins, minerals, flavonoids, alkaloids, sterols, polyphenols, coumarins, triterpenes, lipids and fatty acids etc [1]. The antioxidant activity of $P C J$ may be responsible for its beneficial antipsychotic action.

Furthermore, the presence of kaempferol and quercetin in $P C J$ helps in restoring cerebral blood flow and protect the neurons against inflammatory processes leading to cell injury [17]. $P C J$ contains carotenoids and vitamin, which has antioxidant and neuroprotective property, which in turn protects the neurons from apoptosis [18].

The therapeutic and pharmacological actions of $P C J$ such as antiinflammatory, sedative, antioxidant, antiradical, hypolipidemic, hypoglycemic, anti-ageing, wound healing and antimicrobial are 
noteworthy [1]. Flavonoids present in Pear Juice have potential to prevent neurodegeneration and stimulate neuronal regeneration. Furthermore, Flavonoids have the capacity to cross the blood-brain barrier and prevent inflammatory processes leading to nerve injury. Hydrogen peroxide is generated with the help of MAO and linked to nonbound iron molecules, causing oxidative damage of the cells. Flavonoids present in Pear juice inhibit MAO enzyme, thereby neutralizing oxidative stress [17]. $P C J$ contains, Quercetin, a major flavonoid, possessing antitumor, antithrombotic, anti-inflammatory, anti-apoptotic, and antioxidant effects. Quercetin was found to be neuroprotective not only in a zebrafish model but also was beneficial in reducing ischemia related brain swelling and brain injury [19].

NADPH oxidase, a membrane-bound enzyme, produces superoxide radical in the brain, which is identified as one of the major contributors to oxidative stress. Natural polyphenols present in $P C J$ not only inhibit this NADPH oxidase enzyme but also activate endothelial nitric oxide synthase (eNOS) in the brain. This activated endothelial nitric oxide synthase produces nitric oxide, which further inhibits NADPH oxidase. This protective effect of natural polyphenols may be important in the prevention of brain damage due to ischemic stroke, neuronal apoptosis and neurodegenerative diseases [20].

There are many reports suggesting the role of vitamin- $B$ in the pathogenesis of neurocognitive impairments [21]. Therefore, availability of vitamin-B in $P C J$ might be advantageous in preventing neurocognitive impairments.

The structure and function of a neuron is critical as the cell must maintain appropriate electrical gradients across the membrane, with normal anchor receptors and the ion channels in proper position to communicate with other cells, and be able to release/reuptake unmetabolised neurotransmitters. All these steps depend upon the fatty acid composition of neuronal membrane, which decline with age. Moreover, Long-chain polyunsaturated fatty acids (LC-PUFA) are essential for normal development of brain structures and its functions. Hence, Diet deficient in fatty acids will impair cognitive functions. It is, therefore, possible that a disturbance in the metabolism of LC-PUFA participates in the aetiology of schizophrenia, depression and other mental disorders. The content of polyunsaturated fatty acids has been found to be reduced in the membranes of cerebral tissue as well as red blood cells, skin fibroblasts and plasma of schizophrenic patients in post-mortem studies. Consuming polyunsaturated fatty acids has been shown to slow cognitive decline in animals and humans. Therefore, the dietary supplementation such as Pear Juice has been found to improve membrane fluidity and PUFA content. In addition, PUFA can directly promote neuronal function and neuroprotection [22].

In schizophrenic patients, there are evidence of a decrease in a number of muscarinic receptors. In many studies, anticholinergic drugs were given to the schizophrenic patients, and the effects were observed and quantified. The results showed that choline esterase inhibitors improve cognitive functions of these patients [22]. Fortunately, when $P C J$ was administered to mice for $21 \mathrm{~d}$, it showed a remarkable decrease in acetylcholinesterase activity. $P C J$ contains a fairly good amount of choline [1], which in turn serves as a precursor for the synthesis of acetylcholine, thereby enhancing cholinergic transmission in the brain. It is noteworthy to mention that choline is essential for maintaining and improving overall brain function. Furthermore, inhibition of AChE activity by $P C J$ observed in the present study also leads to enhanced cholinergic transmission desired for improving cognitive function.

In the present project, the antipsychotic activity of $P C J$ was investigated using Ketamine-induced stereotypic behaviour, pole climb avoidance in rats and swim-induced grooming behaviour model. Ketamine-induced stereotypy is a commonly employed interoceptive behavioural model to evaluate antipsychotic potential new medicines. Ketamine, a dissociative anaesthetic, specifically blocks NMDA receptors causing hallucinations in humans, as well as stereotyped behaviour (schizophrenia-like psychosis) and social withdrawal in both rats and humans, thereby reproducing the symptoms of schizophrenia. In the light of these observations, it appears that schizophrenia results from hypoactivity of glutamateergic transmission in the brain. Ketamine produced stereotypic behaviour such as abnormal falling, head-bobbing, weaving and turning behavior through blockade of NMDA receptors in the present study. Haloperidol and Olanzapine (antipsychotic agents) were used in the present study as standard antipsychotic agents. Administration of $P C J$ for 21 successive days in different concentrations showed significant inhibition of stereotypic behaviour in mice as reflected by reduced turning, weaving, headbobbing counts and ataxia. This antipsychotic response of $P C J$ may be due to the presence of glycine, which is an agonist for NMDA receptors. Therefore, it appears that $P C J$ could reverse the stereotypic behaviour induced by Ketamine by displacing Ketamine from NMDA receptors. Furthermore, $P C J$ is rich in glutamic acid content, which promotes the synthesis of glutamate in mesolimbic pathway. This endogenous glutamate might have activated NMDA receptors, which appear to be interlinked with GABA-ergic neurons resulting in enhanced levels of GABA, which in turn decreased release of dopamine thereby showing anti-psychotic effect. Swim induced grooming behaviour in mice involves a dopaminergic mechanism since it was inhibited in a dose-dependent manner by dopamine receptor antagonists such as haloperidol and olanzapine in the present study. Hyperactivity of dopamine within mesolimbic system causes bizarre symptoms (hallucinations, strange behaviour, irrational statements and hostile behaviour], and cognitive dysfunction [4]. In the present study, $P C J$ significantly reduced swiminduced grooming behaviour as well as significantly decreased brain dopamine levels dose-dependently [8]. This confirmed that PCJ possessed promising antipsychotic activity probably mediated through its dopamine D2 receptor blocking action.

Pole-climb avoidance in rats is often used for differentiating neuroleptic activity and sedative property. Administration of PCJ for 21 successive days in different concentrations significantly delayed the latency time taken by the animals to climb the pole in Cook's Pole Apparatus. Since, PCJ produced consistent antipsychotic activity in different antipsychotic models; it appears to be a promising antipsychotic agent.

\section{CONCLUSION}

Pear is one of the best and buttery gifts of God to the mankind. The outcome of present investigation exhibited significant antipsychotic potential of Pear for the first time in animal experiments. Previous preclinical studies of Pear reported several useful medicinal properties of Pear such as anti-inflammatory, sedative, antioxidant, hypolipidemic, hypoglycemic and wound healing property. The anti-psychotic effect exhibited by Pear in the present study can be attributed to the presence of antioxidants like glutathione, Vitamin C, Vitamin E, flavonoids, and polyphenolic compounds, which protect brain cells from the oxidative stress. The presence of glycine and glutamic acid in Pear probably activated NMDA receptors causing diminished dopaminergic transmission via GABA-mediated indirect pathway. This beneficial effect of Pear could be helpful in alleviating bizarre symptoms of psychosis. Furthermore both, inhibition of AChE activity by chronic consumption of Pear and presence of choline in Pear enhanced cholinergic transmission in brains of rodents, which may be responsible for reversing cognitive dysfunctions. Thus, when these findings are extended to the clinical situation, chronic consumption of Pear juice may be useful in reversing bizarre symptoms and managing cognitive dysfunctions of psychosis due to its multifaceted actions.

\section{CONFLICT OF INTERESTS}

\section{Declared none}

\section{REFERENCES}

1. Parle M, Arzoo. Why is pear so dear. Int J Res Ayu Pharm 2016;7:108-13.

2. Li X, Zhang JY, Gao WY, Wang Y, Wang HY, Cao JG, et al. Chemical composition and anti-inflammatory and antioxidant activities of eight pear cultivars. J Agric Food Chem 2012;60:8738-44.

3. Sharma K, Pasricha V, Satpathy G, Gupta RK. Evaluation of the phytochemical and antioxidant activity of raw Pyrus communis (l), an underexploited fruit. J Pharmacogn Phytochem 2015;3:46-50.

4. Parle M, Arzoo. Honey: a sweet way to cure psychosis. Eur J Biomed Pharma Sci 2016;7:479-86. 
5. Parle M, Kadian R, Kaura S. Non-behavioral models of psychosis. Int J Pharm 2013;4:89-95.

6. Hashimoto A, Yoshikawa M, Niwa A, Konno R. Mice lacking Damino acid oxidase activity display marked attenuation of stereotypy and ataxia induced by MK-801. Brain Res 2005; 1033:210-5.

7. Parle M, Kadian R. Behavioral models of psychosis. Int J Pharm 2013:4:26-30.

8. Ingale SP, Kasture SB. Psychopharmacological profile of passiflora incarnata linn in mice. Int J Phytopharmacol 2012;3:263-8.

9. Schlumpf M, Lichtensteiger W, Langemann H, Waser PG, Hefti F. A fluorimetric micromethod for the simultaneous determination of serotonin, noradrenaline and dopamine in milligram amounts of brain tissue. Biochem Pharmacol 1974;23:2337-46.

10. Ellman GL, Courtney KD, Andres V Jr, Feather-Stone RM. A new and rapid colorimetric determination of acetylcholinesterase activity. Biochem Pharmacol 1961;7:88-95.

11. Ellman G. Tissue sulphydryl groups. Arch Biochem Biophys 1959;82:70-3

12. Boskovic M, Vovk T, Plesnicar BK, Grabnar I. Oxidative stress in schizophrenia. Curr Neuropharmacol 2011;9:301-12.

13. Ciobica1 A, Padurariu M, Dobrin I, Stefanescu C, Dobrin R. Oxidative stress in schizophrenia-focusing on the main markers. Psychiatr Danub 2011;23:237-45.
14. Byron KY, Tsung-Ung WW. Oxidative stress in schizophrenia: an integrated approach. Neurosci Biobehav Rev 2011;35:878-93.

15. Hamid AA, Aiyelaagbe O0, Usman LA, Ameen OM, Lawal A Antioxidants: Its medicinal and pharmacological applications. Afr J Pure Appl Chem 2010:4:142-51.

16. Mueller L, Boehm V. Antioxidant activity of $\beta$-carotene compounds in different in vitro assays. Mol 2011;16:1055-69.

17. Jager AK, Saaby L. Flavonoids and the CNS. Mol 2011;16:1471-85.

18. Kale MA, Bindu SM, Khadkikar P. Role of antioxidants and nutrition in oxidative stree: a review. Int J Appl Pharm 2015;7:1-4.

19. Koppula S, Kumar H, More SV, Kim BW, Kim IS, Choi DK. Recent advances on the neuroprotective potential of antioxidants in experimental models of Parkinsonism's disease. Int J Mol Sci 2012;13:10608-29.

20. Kovacsova M, Barta A, Parohova J, Vrankova S, Pechanova O. Neuroprotective mechanisms of natural polyphenolic compounds. Activ Nerv Super Rediv 2010;52:181-6.

21. Nachum-Biala Y, Troen AM. B-vitamins for neuroprotection: narrowing the evidence gap. Int Un Biochem Mol Biol 2012;38:145-50.

22. Rubeša G, Gudelj L, Kubinska N. Etiology of schizophrenia and therapeutic options. Psychiatr Danub 2011;23:308-15.

\section{How to cite this article}

- $\quad$ Arzoo, Milind Parle. Anti-psychotic activity of Pyrus communis juice. Int J Pharm Pharm Sci 2017;9(4):113-120. 